\title{
Letter \\ Use of methotrexate therapy is not associated with decreased prevalence of metabolic syndrome
}

\author{
Hennie G Raterman ${ }^{1}$, Alexandre E Voskuyl1, Ben AC Dijkmans ${ }^{1,2}$ and Michael T Nurmohamed2,3
}

\begin{abstract}
1'Department of Rheumatology, VU University Medical Center, De Boelelaan 1117, $1081 \mathrm{HV}$, Amsterdam, The Netherlands
2Department of Rheumatology, Jan van Breemen Institue, Dr Jan van Breemenstraat 2, 1056 AB Amsterdam, The Netherlands

${ }^{3}$ Department of Internal Medicine, VU University Medical Center, De Boelelaan 1117, 1081 HV, Amsterdam, The Netherlands
\end{abstract}

Corresponding author: Michael T Nurmohamed, mt.nurmohamed@vumc.nl

Published: 21 September 2009

This article is online at http://arthritis-research.com/content/11/5/413

(c) 2009 BioMed Central Ltd
Arthritis Research \& Therapy 2009, 11:413 (doi:10.1186/ar2805)

See related research by Toms et al., http://arthritis-research.com/content/11/4/R110, and related letter by Toms et al., http://arthritis-research.com/content/11/5/414

With great interest, we read the article by Toms and colleagues [1] in the previous issue of Arthritis Research \& Therapy, in which they assessed prevalences of metabolic syndrome (MetS) in rheumatoid arthritis (RA) patients. Moreover, they identified demographic and clinical factors that may be associated with MetS. Toms and colleagues found prevalences of up to $45 \%$ of MetS and demonstrated older age and health status (health assessment questionnaire) to be associated with MetS irrespectively of the definition used. Of most interest, an association between methotrexate (MTX) use and decreased presence of MetS was observed in patients more than 60 years of age. The investigators hypothesized that this may be attributed to a drug-specific effect (and not to an anti-inflammatory effect) either by changing levels of adenosine, which is known to interact with glucose and lipid metabolism, or by an indirect effect mediated through concomitant folic acid administration, thereby decreasing homocysteine levels.

Recently, we also examined the prevalence of MetS in (a subgroup of) RA patients in the CARRÉ investigation, a prospective cohort study on prevalent and incident cardiovascular disease and its underlying cardiovascular risk factors [2]. The findings of Toms and colleagues stimulated us to perform additional analyses in our total study population $(n=353)$.

The prevalences of MetS were 35\% and 25\% (Table 1) according to criteria of National Cholesterol Education Program (NCEP) 2004 and NCEP 2001, respectively. In multivariate backward regression analyses, we found significant associations between body mass index, pulse rate, creatinine levels, hypothyroidism and diabetes mellitus and the presence of MetS independently of the criteria used
(Table 2). However, an independent association between single use of MTX or use of MTX in combination with other disease-modifying antirheumatic drugs, on the one hand, and a decreased prevalence of MetS, on the other hand, could not be demonstrated (even in the subgroup of patients over the age of 60).

Therefore, to get more support for a drug-specific effect, it is of interest to know whether or not in the study of Toms and colleagues the MTX effect was present only in the group of RA patients with single use of MTX or in the group of MTX-treated patients with other antirheumatic drugs. As patients with MetS were significantly older, it would give further information whether age was an independent risk factor for MetS in regression analyses. Moreover, as readers, we are not informed about comorbidities like diabetes and clinical hypothyroidism, which are notorious cardiometabolic risk factors. On the whole, we could not confirm a plausible protective role for the use of MTX and presence of MetS, and hence further investigation is required to explain the discrepancy between our findings and those of Toms and colleagues.

\section{Competing interests}

The authors declare that they have no competing interests.

\section{References}

1. Toms TE, Panoulas VF, Douglas KMJ, Kitas GD: Methotrexate therapy associates with a reduced prevalence of the metabolic syndrome in rheumatoid arthritis patients over the age of 60: more than just an anti-inflammatory effect? A crosssectional study. Arthritis Res Ther 2009, 11:R110.

2. Raterman HG, van Eijk IC, Voskuyl AE, Peters MJ, Dijkmans BA, van Halm VP, Simsek S, Lems WF, Nurmohamed MT: The metabolic syndrome is amplified in hypothyroid rheumatoid arthritis patients: a cross-sectional study. Ann Rheum Dis 2008 Dec 22. [Epub ahead of print]. 
Table 1

\section{Characteristics of the study population}

\begin{tabular}{|c|c|c|c|c|c|c|}
\hline & $\begin{array}{l}\text { MetS presenta } \\
n=84\end{array}$ & $\begin{array}{c}\text { MetS absent }{ }^{\mathrm{a}} \\
\mathrm{n}=265\end{array}$ & $\begin{array}{c}\text { MetS present }{ }^{\mathrm{b}} \\
\mathrm{n}=121\end{array}$ & $\begin{array}{c}\text { MetS absent }{ }^{b} \\
n=228\end{array}$ & $P$ value $^{\mathrm{a}}$ & $P$ value $^{\mathrm{b}}$ \\
\hline \multicolumn{7}{|l|}{ Demographics } \\
\hline Age, years & $63.8( \pm 8)$ & $63.1( \pm 7)$ & $64.3( \pm 8)$ & $62.7( \pm 7)$ & 0.46 & 0.045 \\
\hline Female, percentage & 76 & 63 & 74 & 62 & 0.022 & 0.028 \\
\hline \multicolumn{7}{|l|}{ RA-related characteristics } \\
\hline DAS28 & $4.2( \pm 1.3)$ & $3.9( \pm 1.4)$ & $4.1( \pm 1.3)$ & $3.8( \pm 1.4)$ & 0.21 & 0.062 \\
\hline ESR, mm/hour & $22(10-35)$ & $16(9-30)$ & $20(10-34)$ & $17(9-31)$ & 0.059 & 0.33 \\
\hline $\mathrm{CRP}, \mathrm{mg} / \mathrm{L}$ & $11(4-21)$ & $6(3-16)$ & $8(3-18)$ & $6(3-19)$ & 0.021 & 0.46 \\
\hline RA duration, years & $7(4-10)$ & $7(4-10)$ & $7(4-10)$ & $7(5-10)$ & 0.83 & 0.19 \\
\hline Erosion, percentage & 77 & 83 & 79 & 83 & 0.20 & 0.36 \\
\hline Number of DMARDs & $1(1-2)$ & $1(1-1)$ & $1(1-2)$ & $1(1-1)$ & 0.26 & 0.43 \\
\hline MTX current, percentage & 62 & 60 & 63 & 59 & 0.71 & 0.46 \\
\hline MTX only, percentage & 39 & 39 & 41 & 38 & 0.95 & 0.67 \\
\hline SSZ only, percentage & 8 & 13 & 9 & 14 & 0.23 & 0.22 \\
\hline HCQ only, percentage & 1 & 4 & 3 & 4 & 0.31 & 0.55 \\
\hline Combination of DMARDs, percentage & 31 & 25 & 29 & 25 & 0.24 & 0.38 \\
\hline TNF-blocking agent, percentage & 11 & 9 & 11 & 9 & 0.73 & 0.65 \\
\hline Prednisolone only, percentage & 1 & 2 & 3 & 1 & 1.00 & 0.42 \\
\hline \multicolumn{7}{|l|}{ Cardiovascular risk factors } \\
\hline Current smoker, percentage & 26 & 31 & 25 & 32 & 0.42 & 0.15 \\
\hline Pack-years, years & $17(0-34)$ & $19(2-38)$ & $19(0-35)$ & $18(2-38)$ & 0.23 & 0.75 \\
\hline $\mathrm{BMl}, \mathrm{kg} / \mathrm{m}^{2}$ & $30( \pm 4)$ & $26( \pm 5)$ & $29( \pm 4)$ & $25( \pm 5)$ & $<0.001$ & $<0.001$ \\
\hline Creatinine, $\mu \mathrm{mol} / \mathrm{L}$ & $89( \pm 21)$ & $89( \pm 16)$ & $91( \pm 22)$ & $87( \pm 14)$ & 0.99 & 0.070 \\
\hline Renal clearance, $\mathrm{mL} /$ minute & $81( \pm 24)$ & $72( \pm 19)$ & $77( \pm 23)$ & $73( \pm 19)$ & 0.003 & 0.062 \\
\hline Pulse, beats per minute & $76( \pm 11)$ & $73( \pm 9)$ & $75( \pm 11)$ & $73( \pm 9)$ & 0.005 & 0.015 \\
\hline Diabetes mellitus, percentage & 14 & 3 & 12 & 3 & $<0.001$ & 0.001 \\
\hline Hypothyroidism, percentage & 12 & 2 & 9 & 2 & 0.001 & 0.003 \\
\hline
\end{tabular}

aMetabolic syndrome (MetS) according to National Cholesterol Education Program (NCEP) 2001; b MetS according to NCEP 2004. Continuous variables are presented as means ( \pm standard deviations) in cases of normal distribution or as medians (interquartile ranges) in cases of nonnormal distribution. BMI, body mass index; CRP, C-reactive protein; DAS28, disease activity score using 28 joint counts; DMARD, diseasemodifying antirheumatic drug; ESR, erythrocyte sedimentation rate; HCO, hydroxychloroquine; MTX, methotrexate; RA, rheumatoid arthritis; SSZ, sulfasalazine; TNF, tumour necrosis factor.

\section{Table 2}

Variables associated with metabolic syndrome

\begin{tabular}{|c|c|c|c|c|c|c|}
\hline & \multicolumn{3}{|c|}{ Univariate } & \multicolumn{3}{|c|}{ Multivariate $^{\mathrm{a}}$} \\
\hline & OR & $95 \% \mathrm{Cl}$ & $P$ value & OR & $95 \% \mathrm{Cl}$ & $P$ value \\
\hline Body mass index & 1.2 & $1.1-1.3$ & $<0.001$ & 1.2 & $1.1-1.3$ & $<0.001$ \\
\hline Pulse & 1.03 & $1.01-1.06$ & 0.011 & 1.03 & $1.00-1.06$ & 0.020 \\
\hline Creatinine & 1.01 & $1.00-1.02$ & 0.080 & 1.02 & $1.00-1.03$ & 0.017 \\
\hline Hypothyroidism & 4.5 & 1.5-13.2 & 0.007 & 4.7 & $1.5-15.0$ & 0.009 \\
\hline Diabetes mellitus & 4.8 & $1.8-12.9$ & 0.002 & 4.5 & $1.4-15.2$ & 0.014 \\
\hline
\end{tabular}

aln multivariate analyses, the following variables were used: gender, age, prednisolone only, methotrexate only, sulfasalazine only, hydroxychloroquine only, tumour necrosis factor-blocking agents, combination of disease-modifying antirheumatic drugs, pack-years, smoking, erosions, DAS28 (disease activity score using 28 joint counts), body mass index, pulse rate, creatinine levels, renal clearance, hypothyroidism and diabetes mellitus. $\mathrm{Cl}$, confidence interval; OR, odds ratio. 